British Journal of Nutrition (2022), 127, 92-102

doi: $10.1017 /$ S0007114521000751

(C) The Author(s), 2021. Published by Cambridge University Press on behalf of The Nutrition Society. This is an Open Access article, distributed under the terms of the Creative Commons Attribution-NonCommercial-NoDerivatives licence (http://creativecommons.org/licenses/by-nc-nd/ $4.0 /$, which permits non-commercial re-use, distribution, and reproduction in any medium, provided the original work is unaltered and is properly cited. The written permission of Cambridge University Press must be obtained for commercial re-use or in order to create a derivative work.

\title{
Anthropometric cut-points for discriminating diabetes and the metabolic syndrome among Arabs and Asians: the Kuwait Diabetes Epidemiology Program
}

\author{
Victor M. Oguoma ${ }^{1,2,3}$, Neil T. Coffee ${ }^{1}$, Saad Alsharrah ${ }^{1,2}$, Mohamed Abu-Farha ${ }^{4}$, Faisal H. Al-Refaei ${ }^{2}$, \\ Abdullah Alkandari ${ }^{5}$, Fahd Al-Mulla ${ }^{5}$ and Mark Daniel ${ }^{1,6}$ \\ ${ }^{1}$ Health Research Institute, University of Canberra, Canberra, Australia \\ ${ }^{2}$ Geohealth Laboratory, Dasman Diabetes Institute, Kuwait City, Kuwait \\ ${ }^{3}$ Menzies School of Health Research, Charles Darwin University, Darwin, Australia \\ ${ }^{4}$ Biochemistry and Molecular Biology Department, Dasman Diabetes Institute, Kuwait City, Kuwait \\ ${ }^{5}$ Genetics and Bioinformatics Department, Dasman Diabetes Institute, Kuwait City, Kuwait \\ ${ }^{6}$ Department of Medicine, St. Vincent's Hospital, The University of Melbourne, Melbourne, Australia \\ (Submitted 3 November 2020 - Final revision received 9 February 2021 - Accepted 25 February 2021 - First published online 4 March 2021)
}

\section{Abstract}

This study aimed to determine anthropometric cut-points for screening diabetes and the metabolic syndrome (MetS) in Arab and South Asian ethnic groups in Kuwait and to compare the prevalence of the MetS based on the ethnic-specific waist circumference (WC) cut-point and the International Diabetes Federation (IDF) and American Heart Association/National Heart, Lung, and Blood Institute WC criteria. The national population-based survey data set of diabetes and obesity in Kuwait adults aged 18-60 years was analysed. Age-adjusted logistic regression and receiver operating characteristic (ROC) analyses were conducted to evaluate for 3589 individuals the utility of WC, waist:height ratio (WHtR) and BMI to discriminate both diabetes and $\geq 3$ CVD risk factors. Areas under the ROC curve were similar for WC, WHtR and BMI. In Arab men, WC, WHtR and BMI cut-offs for diabetes were $106 \mathrm{~cm}, 0.55$ and $28 \mathrm{~kg} / \mathrm{m}^{2}$ and for $\geq 3$ CVD risk factors, $97 \mathrm{~cm}, 0.55$ and $28 \mathrm{~kg} / \mathrm{m}^{2}$, respectively. In Arab women, cut-offs for diabetes were $107 \mathrm{~cm}, 0.65$ and $33 \mathrm{~kg} / \mathrm{m}^{2}$ and for $\geq 3$ CVD risk factors, $93 \mathrm{~cm}, 0.60$ and $30 \mathrm{~kg} / \mathrm{m}^{2}$, respectively. WC cut-offs were higher for South Asian women than men. IDF-based WC cut-offs corresponded to a higher prevalence of the MetS across sex and ethnic groups, compared with Kuwait-specific cut-offs. Any of the assessed anthropometric indices can be used in screening of diabetes and $\geq 3$ CVD risk factors in Kuwaiti Arab and Asian populations. ROC values were similar. The WC threshold for screening the MetS in Kuwaiti Arabs and South Asians is higher for women.

Key words: The metabolic syndrome: Waist circumference: Waist:height ratio: BMI: Kuwait

The metabolic syndrome (MetS) is the constellation of risk factors associated with greater risk of developing type 2 diabetes and $\mathrm{CVD}^{(1)}$. These risk factors of metabolic origin include hyperglycaemia, dyslipidaemia (elevated TAG and lowered HDLcholesterol), obesity and hypertension. Collectively termed the 'metabolic syndrome', most underlying risk factors can be modified through behavioural and/or pharmaceutical intervention ${ }^{(2)}$. Given that the MetS increases in prevalence as obesity prevalence in the population increases, it was introduced as a diagnostic category for early identification of, and intervention on, individuals at high risk of metabolic disease, with the goal of reducing the risk of developing type 2 diabetes and $\mathrm{CVD}^{(3)}$.
Central obesity ${ }^{(4)}$ and insulin resistance ${ }^{(5)}$ have long been implicated in driving the initiation and development of the MetS; however, there remains uncertainty regarding the key underlying mechanism of its development. Gut microbiota ${ }^{(6)}$, chronic stress $^{(7)}$, dietary $n$ - 3 fatty acid deficiency and high fructose intake ${ }^{(8)}$ have all been connected to the development of the MetS. However, recent guidelines have laid more emphasis on central obesity ${ }^{(2)}$.

In Kuwait and other countries in the Gulf Cooperation Council, a relatively recent phenomenon has been a major lifestyle transition defined by high energetic intake and unprecedented low physical activity levels ${ }^{(9)}$. This lifestyle is thought

Abbreviations: AHA/NHLBI, American Heart Association/National Heart, Lung, and Blood Institute; ATP III, Adult Treatment Panel III; IDF, International Diabetes Federation; MetS, metabolic syndrome; ROC, receiver operating characteristic; WC, waist circumference; WHtR, waist:height ratio; BMI, body mass index; CVD, cardiovascular disease; HDL, high-density lipoprotein cholesterol; TAG, triacylglycerol.

* Corresponding author: Dr Victor M. Oguoma, email victor.oguoma@canberra.edu.au 
to be substantially contributing to high rates of overweight and obesity in the Gulf region and the resultant cluster of risk factors leading to the MetS. Reports of MetS prevalence in Kuwait vary by sex, depending on the MetS classification used, such as those from the International Diabetes Federation (IDF) and National Cholesterol Education Program Adult Treatment Panel III (ATP III). Women have been reported to have MetS prevalence of $37.7 \%$ and $40.1 \%$ per ATP III and IDF criteria, respectively, and men, $34.2 \%$ and $41.7 \%$, respectively ${ }^{(9)}$. These prevalence rates are comparable to reports in high-income countries such as USA, $34.7 \%{ }^{(10)}$ and Australia, $33.5 \%{ }^{(11)}$.

Prognostic risk assessment tools for early identification of type 2 diabetes and CVD exist. These include, but are not limited to, the Framingham risk assessment tool ${ }^{(12)}$, Finish diabetes risk score $^{(13)}$, systematic coronary risk evaluation risk charts ${ }^{(14)}$, UK prospective diabetes study risk engine ${ }^{(15)}$, European IR Risk Index and European HTN Risk Index ${ }^{(16)}$. However, the prospective population used to design these risk assessment tools did not include the Kuwaiti population. As the Framingham risk assessment tool classifies as 'low risk' some $23 \%$ of individuals with the $\mathrm{MetS}^{(17)}$ and evidence that the MetS predicts a 2- to 3-fold greater risk of incident CVD morbidity and mortality $(18,19)$, there is a need for stronger attention to the MetS in screening cardiometabolic risk. Importantly, key independent CVD risk factors (hypertriacylglycerolaemia, hyperglycaemia and obesity) incorporated in the definition of the MetS are not even captured by some risk assessment tools.

Several definitions of the MetS have been promoted ${ }^{(2,20-25)}$. The American Heart Association/National Heart, Lung, and Blood Institute (AHA/NHLBI) made minor changes to the ATP III criteria to include impaired fasting glucose at $\geq 5.5$ $\mathrm{mmol} / \mathrm{l}$. Countries such as Kuwait have used different definitions in different surveys, but whichever definition has been used, the MetS estimate is based on anthropometric norms for non-Middle East populations. A review by Ansarimoghaddam et $a l .^{(26)}$ reported that, in the Middle East, the $\operatorname{IDF}^{(24)}$ and ATP III ${ }^{(21)}$ definitions were most commonly used. Just one study of Middle East populations used the definition proposed by the Joint Interim Statement on harmonising the definition of the $\mathrm{MetS}^{(2)}$. Of fifty-nine Middle East MetS studies in the pooled analysis, only eight studies were from Kuwait; of these, one used both ATP III and IDF definitions, three used ATP III, three others used IDF and one used the Joint Interim Statement definition. The use of varied definitions yields variations in estimated prevalence rates and difficulty in comparing the burden of the MetS across studies and countries. The Joint Interim Statement on harmonising the definition of the MetS was formalised in $2009^{(2)}$ to promote uniformity in measuring the MetS and agreed on four components for defining the MetS. However, the waist circumference (WC) cut-point for central obesity remains controversial in its application to different ethnic groups ${ }^{(27)}$.

Based on the Joint Interim Statement, Arabs from the Eastern Mediterranean and Middle East ethnic groups have been recommended thus far to be screened for central obesity using the Europid ethnic threshold (WC $\geq 94 \mathrm{~cm}$ for men and $\geq 80 \mathrm{~cm}$ for women), until more specific data are available. South Asians on the other hand are recommended to be screened using the ethnic-specific cut-off of $\mathrm{WC} \geq 90 \mathrm{~cm}$ for men and $\geq 80 \mathrm{~cm}$ for women $^{(2)}$. This reflects Asians' tendency to have a higher percentage of body fat at lower BMI and WC than Europeans, predisposing a higher prevalence of the MetS at lower BMI and $\mathrm{WC}^{(28,29)}$. Beyond BMI and WC indices, increasing evidence from different ethnic groups has shown that waist:height ratio (WHtR) is a better predictor of the MetS than BMI and $\mathrm{WC}^{(30-33)}$.

The objectives of this study were to determine, for Arabs and South Asian expatriates living in Kuwait (the most highly dominant non-Arab ethnic group in Kuwait), (a) ethnic-specific WC, WHtR and BMI cut-points for screening diabetes and the MetS and (b) to compare the prevalence of the MetS based on the ethnic-specific WC cut-point and the IDF, and American Heart Association/National Heart, Lung, and Blood Institute (AHA/NHLBI) WC criteria (the updated ATP III criteria).

\section{Methods}

\section{Study design and participants}

A national population-based cross-sectional survey of diabetes and obesity in Kuwait, part of the Kuwait Diabetes Epidemiology Program, was conducted between 2011 and 2014, targeting adults aged 18-82 years (Kuwaiti and non-Kuwaiti). A stratified random sample of participants by nationality and governorate from the computerised register of the Public Authority for Civil Information was used as earlier reported ${ }^{(34)}$. A total of 4963 participants had valid records for sex, age and $\mathrm{BMI}^{(34)}$. Participants were excluded if they had missing records for any of WC ( $n$ 42) and fasting blood glucose ( $n 6$ ); WC $>150$ and $<50$ ( $n$ 12), medical history of diabetes ( $n$ 921) and ethnicity other than Arab and South Asian ( $n$ 393). The WC $<50 \mathrm{~cm}(n$ 3) and $>150 \mathrm{~cm}(n$ 9) was considered data entry error. A total of 3589 participants remained for analysis. South Asian expatriates residing in Kuwait were predominantly from India, Pakistan, Sri Lanka and Bangladesh; Arab groups were mainly from Kuwait, Egypt, Lebanon, Syria, Jordan, Iran, Palestine and Yemen.

\section{Anthropometric and physical measurements}

Anthropometric measurements were carried out on participants in light clothing and barefoot. Height and weight were measured using a human digital column weighing scale with a mounted stadiometer (SECA), and the ratio of weight ( $\mathrm{kg}$ ):height square $\left(\mathrm{m}^{2}\right)$ was calculated to express BMI ${ }^{(25)}$. WC was measured using a constant tension tape (SECA), with arms relaxed at the sides, at the highest point of the iliac crest and the mid-axillary line. The ratio of WC $(\mathrm{cm})$ :height $(\mathrm{m})$ was used to define the WHtR values. Blood pressure was measured using an Omron HEM-907XL digital sphygmomanometer (Omron Healthcare, Inc.). The average of three readings of each of systolic and diastolic blood pressure ( $\mathrm{mmHg}$ ) was calculated to express blood pressure.

\section{Biochemical measurements}

Study participants fasted for at least $10 \mathrm{~h}$ prior to the collection of fasting blood samples. Siemens Dimension RXL chemistry analyser (Diamond Diagnostics) was used to measure the blood glucose and lipids profile. Participants were measured for HbA1c using a Variant device (Bio-Rad Laboratories). All blood analyses 
were conducted at the Dasman Diabetes Institute clinical laboratories.

\section{Definition of the metabolic syndrome and risk factors}

Hypertension was defined as systolic blood pressure $\geq 130 \mathrm{mmHg}$ and/or diastolic blood pressure $\geq 85 \mathrm{mmHg}$ and/ or receiving treatment for such condition ${ }^{(2)}$. In lieu of an ethnic-specific cut-point, the WC cut-point for Europid ethnicity was applied to define central obesity for Arabs. The ethnicspecific cut-off for South Asians was used to define central obesity for this group ${ }^{(2)}$. These relevant cut-offs for men and women were $\mathrm{WC} \geq 94 \mathrm{~cm}$ and $\geq 80 \mathrm{~cm}$, respectively, for Arabs, and $\mathrm{WC} \geq 90 \mathrm{~cm}$ and $\geq 80 \mathrm{~cm}$, respectively, for South Asians. Elevated HbA1c $\geq 6 \cdot 5 \%{ }^{(35)}$ or fasting blood glucose $\geq 7.0 \mathrm{mmol} / \mathrm{l}$ was used to define diabetes ${ }^{(2)}$. Hyperglycaemia (fasting blood glucose) was defined as fasting blood glucose $\geq$ $6.1 \mathrm{mmol} / \mathrm{l}^{(2)}$, while dyslipidaemia was defined when at least one lipids disorder (elevated total cholesterol $\geq 5.2 \mathrm{mmol} / \mathrm{l}$, elevated TAG $\geq 1.7 \mathrm{mmol} / \mathrm{l}$, low HDL $\leq 1.03 \mathrm{mmol} / 1$ for men or $\leq 1.29$ for women and elevated $\mathrm{LDL} \geq 2.6 \mathrm{mmol} / \mathrm{l}$ ) is identified $^{(2)}$. We defined $\geq 3$ CVD risk factors as the presence of any three of hyperglycaemia, hypertension, elevated blood TAG and low HDL level. The criteria used in defining the MetS were based on:

- IDF: central obesity and any two of hyperglycaemia, hypertension, elevated blood TAG and low HDL level.

- AHA/NHLBI: is an update of the ATP III criteria. Any three of central obesity, hyperglycaemia, hypertension, elevated blood TAG and low HDL level are required for MetS diagnosis.

For each set of criteria, we compared the IDF ethnic-specific WC cut-off and the predicted WC cut-off from our study population.

\section{Ethical clearance}

This study was conducted at Dasman Diabetes Institute and approved by the Ethical Review Committee (ERC - RA2010004). The study protocol was consistent with the Declaration of Helsinki. All participants signed the consent form, in writing, prior to enrolment in the study.

\section{Statistical analysis}

Analyses were performed separately for sex and ethnic groups. Descriptive statistics were calculated and presented as mean and standard deviation, or median and interquartile ranges if skewed, while categorical variables are presented as counts and percentages.

Age-adjusted logistic regression and receiver operating characteristic (ROC) analyses were carried out to evaluate the ability of anthropometric indices (WC, WHtR and BMI) to discriminate diabetes and $\geq 3$ CVD risk factors. The area under the ROC curve provides a scale from 0.5 to 1.0 that is used to compare the ability of an anthropometric index to detect a positive disease condition. AUC of 0.5 indicates an absence of predictive power, while AUC of 1 indicates a perfect prediction ${ }^{(36)}$. The optimal cut-off points were identified based on Youden's index, which is defined as the points on the ROC curve that maximises the sum of sensitivity and specificity (sensitivity + specificity -1$)$. Sensitivity, specificity, positive and negative predictive values, and their $95 \%$ CI were calculated and presented for cut-points determined for each set of predictive criteria.

Age-adjusted restricted cubic spline regression with three knots at 10, 50 and 90 percentiles was further applied to assess the non-linear relationship between anthropometric indices and diabetes and $\geq 3$ CVD risk factors across sex and ethnic groups. The Wald statistic was used to test the linearity of the relationship between WC, WHtR and BMI and the log-odds of having diabetes or $\geq 3$ CVD risk factors. The respective cut-off points for sex and ethnicity derived based on Youden's index were used as a reference for the estimation of $\mathrm{OR}$.

Point estimates from logistic regression are presented as adjusted OR and $95 \%$ CI. Statistical significance was set at $P<0 \cdot 05$. The WC cut-off points derived for sex and ethnicity subgroups, the IDF and AHA/NHLBI WC cut-off points were used to define the MetS based on the IDF and AHA/NHLBI criteria. The prevalence of the MetS based on these WC cut-off points and MetS criteria was calculated and graphed. All statistical analysis was conducted using Stata 16.1 (StataCorp).

\section{Results}

\section{Basic study characteristics of participants}

Data from 3589 participants were analysed. The sample included 2711 Arabs and 878 Asians with mean ages 43 and 41 years, respectively. Arabs had higher mean WC and BMI than the South Asians residing in Kuwait (Table 1). Across the two groups, women had higher BMI than men, while men had higher WC in the Arab group but not in the South Asian group. Arabs had lower average SBP, DBP and proportion of individuals with hypertension compared with South Asian group. Arab and South Asian men had a higher prevalence of diabetes, hypertension, dyslipidaemia and $\geq 3$ CVD risk factors compared with Arab and South Asian women.

\section{Areas under the receiver operating characteristics curves for various anthropometric indices}

Figure 1 shows the ROC curves for each anthropometric index stratified by sex and ethnic group. The age-adjusted AUC and OR for WC, WHtR and BMI across sex and ethnic group for diabetes and $\geq 3$ CVD risk factors are presented in Table 2 . The AUC were similar for WC, WHtR and BMI, although WC had slightly higher AUC than BMI for diabetes in Arab men and women. BMI and WHtR had the highest AUC for $\geq 3$ CVD risk factors in South Asian women and men, respectively. In Arab and South Asia men and women, BMI and WHtR were associated with a greater odd of diabetes and $\geq 3$ CVD risk factors.

\section{Cut-off points, sensitivities, specificities, positive and negative predictive values}

Table 3 shows the optimal cut-off points, sensitivities, specificities, positive and negative predictive values of each anthropometric index that maximises the classification of participants with diabetes and $\geq 3$ CVD risk factors in comparison with 
Table 1. Basic characteristics of study population

(Numbers and percentages)

\begin{tabular}{|c|c|c|c|c|c|c|c|c|c|c|c|c|}
\hline \multirow[b]{3}{*}{ Factors } & \multicolumn{6}{|c|}{ Arab } & \multicolumn{6}{|c|}{ South Asia } \\
\hline & \multicolumn{2}{|c|}{ Male $(N 1417)$} & \multicolumn{2}{|c|}{ Female (N 1294) } & \multicolumn{2}{|c|}{ Total (N 2711) } & \multicolumn{2}{|c|}{ Male (N609) } & \multicolumn{2}{|c|}{ Female (N 269) } & \multicolumn{2}{|c|}{ Total (N 878) } \\
\hline & mean & SD & mean & SD & mean & SD & mean & SD & mean & SD & mean & SD \\
\hline Age (years) & 43.5 & $10 \cdot 0$ & $42 \cdot 2$ & $9 \cdot 6$ & $42 \cdot 9$ & 9.8 & 40.8 & $9 \cdot 1$ & $41 \cdot 3$ & 8.8 & 41.0 & 9.0 \\
\hline Height $(\mathrm{cm})$ & $172 \cdot 4$ & $6 \cdot 7$ & 158.8 & $5 \cdot 8$ & $165 \cdot 9$ & $9 \cdot 2$ & 169.5 & 6.8 & $157 \cdot 2$ & 5.6 & $165 \cdot 7$ & 8.6 \\
\hline Weight (kg) & 90.6 & $17 \cdot 3$ & 79.5 & $16 \cdot 9$ & $85 \cdot 3$ & $18 \cdot 0$ & $77 \cdot 2$ & 12.9 & 70.9 & 13.7 & $75 \cdot 3$ & $13 \cdot 4$ \\
\hline BMI $\left(\mathrm{kg} / \mathrm{m}^{2}\right)$ & 30.5 & $5 \cdot 3$ & 31.5 & $6 \cdot 4$ & 31.0 & 5.9 & $26 \cdot 8$ & 4.0 & 28.7 & 5.5 & 27.4 & 4.6 \\
\hline WC (cm) & $101 \cdot 3$ & 11.9 & $96 \cdot 0$ & $12 \cdot 7$ & 98.8 & $12 \cdot 6$ & 92.9 & $9 \cdot 7$ & $93 \cdot 3$ & $11 \cdot 8$ & 93.0 & $10 \cdot 4$ \\
\hline WHtR & 0.6 & 0.1 & 0.6 & 0.1 & 0.6 & 0.1 & 0.5 & 0.1 & 0.6 & 0.1 & 0.6 & 0.1 \\
\hline FBG & 5.4 & $1 \cdot 2$ & $5 \cdot 1$ & $1 \cdot 1$ & $5 \cdot 2$ & $1 \cdot 2$ & 5.4 & $1 \cdot 1$ & $5 \cdot 1$ & 0.7 & $5 \cdot 3$ & 1.0 \\
\hline SBP & 131.4 & $22 \cdot 1$ & $119 \cdot 2$ & $15 \cdot 9$ & 125.5 & $20 \cdot 3$ & 134.0 & $16 \cdot 3$ & 123.9 & $18 \cdot 4$ & 130.9 & 17.5 \\
\hline DBP & $79 \cdot 3$ & 11.6 & $75 \cdot 2$ & $10 \cdot 7$ & $77 \cdot 3$ & 11.4 & $82 \cdot 8$ & 11.2 & $78 \cdot 0$ & $11 \cdot 2$ & 81.3 & 11.4 \\
\hline TC & $5 \cdot 3$ & $1 \cdot 0$ & $5 \cdot 2$ & 1.0 & $5 \cdot 2$ & $1 \cdot 0$ & $5 \cdot 3$ & 1.1 & $5 \cdot 2$ & $1 \cdot 0$ & $5 \cdot 2$ & 1.0 \\
\hline TAG & 1.6 & $1 \cdot 0$ & $1 \cdot 2$ & 0.7 & 1.4 & 0.9 & 1.7 & $1 \cdot 2$ & $1 \cdot 2$ & 0.8 & 1.6 & 1.1 \\
\hline $\mathrm{HDL}$ & $1 \cdot 1$ & $2 \cdot 4$ & 1.4 & $2 \cdot 4$ & $1 \cdot 3$ & $2 \cdot 4$ & $1 \cdot 2$ & 3.9 & 1.5 & 4.6 & $1 \cdot 3$ & 4.1 \\
\hline \multirow[t]{2}{*}{ LDL } & 3.5 & 0.9 & 3.3 & 0.9 & 3.4 & 0.9 & 3.5 & $1 \cdot 0$ & 3.4 & 0.8 & 3.5 & 0.9 \\
\hline & $n / N$ & $\%$ & $\mathrm{n} / \mathrm{N}$ & $\%$ & $\mathrm{n} / \mathrm{N}$ & $\%$ & $n / N$ & $\%$ & $n / N$ & $\%$ & $n / N$ & $\%$ \\
\hline Hypertension & $398 / 1415$ & $28 \cdot 1$ & $174 / 1293$ & 13.5 & $572 / 2708$ & $21 \cdot 1$ & $238 / 609$ & 39.1 & $61 / 269$ & $22 \cdot 7$ & $299 / 878$ & $34 \cdot 1$ \\
\hline Elevated FBG & $171 / 1417$ & $12 \cdot 1$ & $106 / 1294$ & $8 \cdot 2$ & $277 / 2711$ & $10 \cdot 2$ & $81 / 609$ & $13 \cdot 3$ & $16 / 269$ & 5.9 & $97 / 878$ & $11 \cdot 0$ \\
\hline Elevated $\mathrm{HbA} 1 \mathrm{c}$ & 133/1415 & 9.4 & $82 / 1293$ & $6 \cdot 3$ & $215 / 2708$ & 7.9 & $75 / 609$ & $12 \cdot 3$ & $26 / 269$ & 9.7 & $101 / 878$ & 11.5 \\
\hline Diabetes & $77 / 1417$ & 5.4 & $41 / 1294$ & $3 \cdot 2$ & $118 / 2711$ & 4.4 & $40 / 609$ & 6.6 & $5 / 269$ & 1.9 & $45 / 878$ & $5 \cdot 1$ \\
\hline Elevated TC & $744 / 1417$ & 52.5 & $632 / 1294$ & $48 \cdot 8$ & $1376 / 2711$ & $50 \cdot 8$ & $322 / 609$ & 52.9 & $133 / 269$ & $49 \cdot 4$ & $455 / 878$ & $51 \cdot 8$ \\
\hline Elevated TAG & $477 / 1417$ & 33.7 & 239/1294 & 18.5 & $716 / 2711$ & $26 \cdot 4$ & $240 / 609$ & 39.4 & $50 / 269$ & $18 \cdot 6$ & $290 / 878$ & 33.0 \\
\hline Elevated LDL & $1199 / 1393$ & $86 \cdot 1$ & $1033 / 1285$ & $80 \cdot 4$ & 2232/2678 & $83 \cdot 3$ & $507 / 597$ & 84.9 & $222 / 269$ & 82.5 & $729 / 866$ & $84 \cdot 2$ \\
\hline Low HDL & $745 / 1415$ & $52 \cdot 7$ & $615 / 1294$ & 47.5 & $1360 / 2709$ & $50 \cdot 2$ & $371 / 609$ & 60.9 & $179 / 269$ & 66.5 & $550 / 878$ & $62 \cdot 6$ \\
\hline Dyslipidaemia & $1330 / 1417$ & 93.9 & $1149 / 1294$ & 88.8 & $2479 / 2711$ & 91.4 & $579 / 609$ & $95 \cdot 1$ & $249 / 269$ & $92 \cdot 6$ & $828 / 878$ & $94 \cdot 3$ \\
\hline 1 of 4 risk factors & $402 / 1417$ & $28 \cdot 4$ & $491 / 1294$ & 37.9 & $893 / 2711$ & $32 \cdot 9$ & $154 / 609$ & $25 \cdot 3$ & $99 / 269$ & $36 \cdot 8$ & $253 / 878$ & 28.8 \\
\hline 2 of 4 risk factors & $510 / 1417$ & 36.0 & $384 / 1294$ & 29.7 & $894 / 2711$ & 33.0 & 212/609 & 34.8 & $91 / 269$ & 33.8 & $303 / 878$ & 34.5 \\
\hline 3 of 4 risk factors & $301 / 1417$ & $21 \cdot 2$ & $155 / 1294$ & $12 \cdot 0$ & $456 / 2711$ & $16 \cdot 8$ & $169 / 609$ & $27 \cdot 8$ & $38 / 269$ & $14 \cdot 1$ & $207 / 878$ & $23 \cdot 6$ \\
\hline 4 of 4 risk factors & $76 / 1417$ & 5.4 & 28/1294 & $2 \cdot 2$ & $104 / 2711$ & 3.8 & $41 / 609$ & 6.7 & $15 / 269$ & 5.6 & $56 / 878$ & 6.4 \\
\hline$\geq 3$ CVD risk factors & $377 / 1417$ & $26 \cdot 6$ & $183 / 1294$ & $14 \cdot 1$ & $560 / 2711$ & $20 \cdot 7$ & $210 / 609$ & 34.5 & $53 / 269$ & $19 \cdot 7$ & $263 / 878$ & $30 \cdot 0$ \\
\hline
\end{tabular}

WC, waist circumference; WHtR, waist:height ratio; FBG, fasting blood glucose; SBP, systolic blood pressure; DBP, diastolic blood pressure; TC, total cholesterol; TAG, triacylglycerol; HDL, high-density lipoprotein cholesterol; LDL, low-density lipoprotein cholesterol.

currently used cut-off points. In Arab men, the optimal cut-offs for WC, WHtR and BMI for predicting diabetes and $\geq 3$ CVD risk factors were $106 \mathrm{~cm}, 0.55$ and $28 \mathrm{~kg} / \mathrm{m}^{2}$ for diabetes and $97 \mathrm{~cm}$, 0.55 and $28 \mathrm{~kg} / \mathrm{m}^{2}$ for $\geq 3 \mathrm{CVD}$ risk factors, respectively. In women, the cut-offs were $107 \mathrm{~cm}, 0.65$ and $33 \mathrm{~kg} / \mathrm{m}^{2}$ for diabetes and $93 \mathrm{~cm}, 0.60$ and $30 \mathrm{~kg} / \mathrm{m}^{2}$ for $\geq 3$ CVD risk factors, respectively. The sample-specific cut-offs for WC, WHtR and BMI for predicting diabetes and $\geq 3$ CVD risk factors among men South Asian expatriates were $92 \mathrm{~cm}, 0.56$ and $23 \mathrm{~kg} / \mathrm{m}^{2}$ for diabetes and $91 \mathrm{~cm}, 0.52$ and $25 \mathrm{~kg} / \mathrm{m}^{2}$ for $\geq 3$ CVD risk factors, respectively. In South Asian women, the cut-off points were $91 \mathrm{~cm}, 0.57$ and $26 \mathrm{~kg} / \mathrm{m}^{2}$ for diabetes and $93 \mathrm{~cm}, 0.49$ and $32 \mathrm{~kg} / \mathrm{m}^{2}$ for $\geq 3$ CVD risk factors, respectively.

Shape of relationship between waist circumference, waist:height ratio and BMI; and diabetes and $\geq 3$ CVD risk factors

Figure 2(a)-(c) shows a non-linear relationship between the anthropometric indices and diabetes and $\geq 3$ CVD risk factors across sex and ethnic groups. At higher WC, WHtR and BMI values, Asian men tend to have higher odds of diabetes and $\geq 3$ CVD risk factors than Arab men and the odds was consistently greater after the anthropometric-specific cut-off points. Conversely, the OR of $\geq 3$ CVD risk factors for women was greater in Arab women compared with South Asian women across the anthropometric indices. However, there is an s-shaped relationship of the point estimates in South Asian women, where the odds of diabetes and $\geq 3$ CVD risk factors for the anthropometric indices plateau after the cut-point.

\section{Prevalence of the metabolic syndrome based on International Diabetes Federation and American Heart Association/National Heart, Lung, and Blood Institute criteria}

Estimated prevalence rates of the MetS based on the IDF and AHA/NHLBI criteria using the IDF ethnic cut-off points and the predicted sample-specific WC cut-off are shown in Figure 3. The IDF WC cut-offs corresponded to a higher prevalence across sex and ethnic groups compared with the sample-specific cut-offs.

\section{Discussion}

Our study of a representative sample of 3589 Kuwaiti Arabs and other Arabs from Middle East and Mediterranean countries and expatriates from South Asia showed that WC and WHtR were slightly more predictive of diabetes and $\geq 3$ CVD risk factors across sex amongst Arabs, while BMI showed slightly higher discriminatory ability of $\geq 3$ CVD risk factors across South Asian women, than WC and WHtR. The similar areas under the ROC 
96

V. M. Oguoma et al.
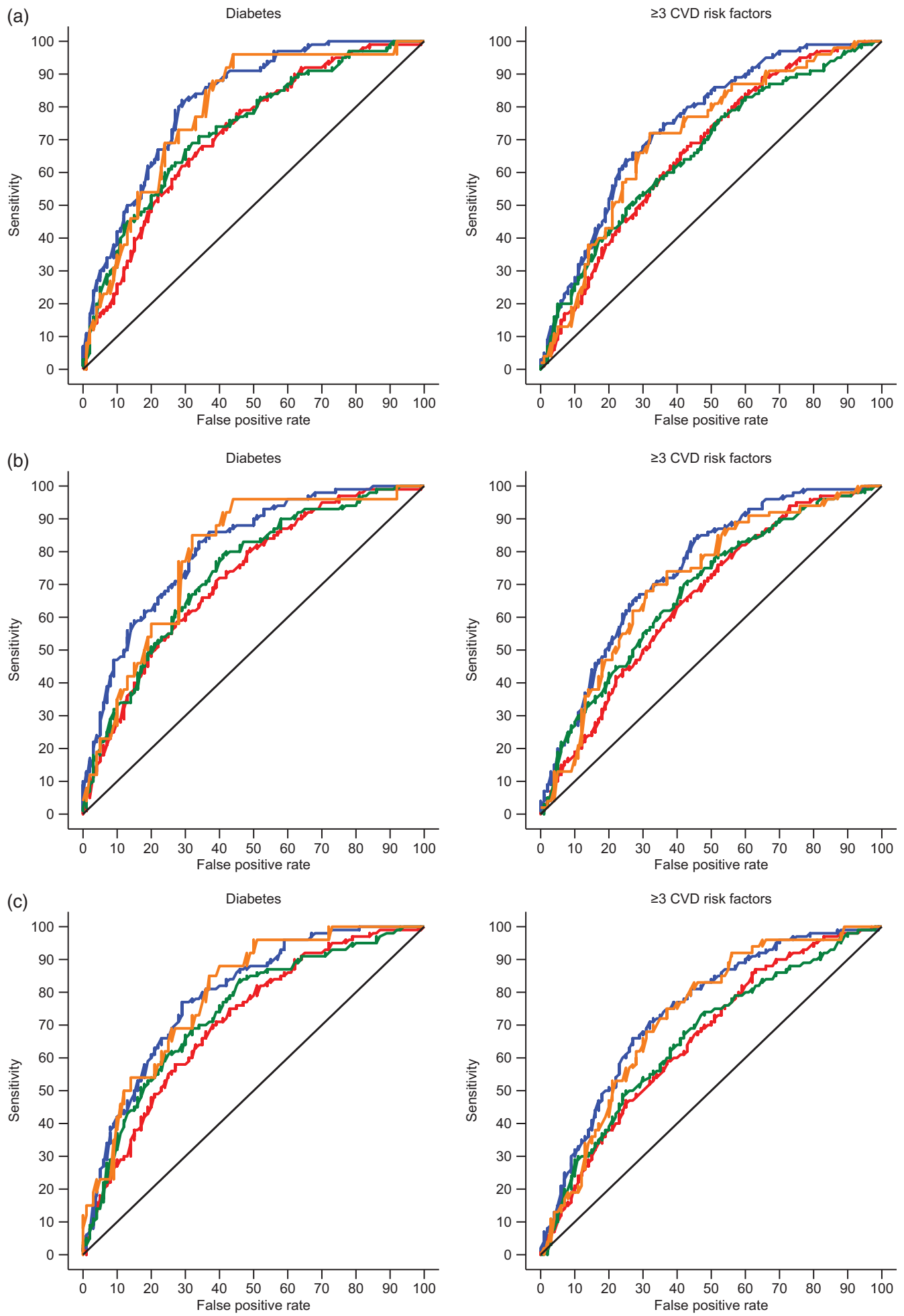

Fig. 1. Non-linear relationship between (a) waist circumference (WC), (b) waist:height ratio (WHtR) and (c) BMI; and diabetes and $\geq 3$ CVD risk factors across sex and ethnic group. —, M, Arab; —, F, Arab; —, M, South Asia; —, F, South Asia.

curves suggest that the use of any one of WC, WHtR and/or BMI would be more time and resource efficient in the screening of diabetes and $\geq 3$ CVD risk factors in the at-risk individuals/ population.
Differing results have emerged from countries in the Middle East and Mediterranean region regarding whether BMI is a better predictor than WC and WHtR of the MetS and related risk factors, or vice versa. ${ }^{(37)}$ Hamzeh et al. ${ }^{(38)}$ reported that BMI had the 
Table 2. Areas under the receiver operating characteristic curves (AUC) for various anthropometric indices and the metabolic syndrome risk factors in South Asia and Arab males and females (Numbers and percentages; adjusted odds ratio (aOR) and $95 \%$ confidence interval)

\begin{tabular}{|c|c|c|c|c|c|c|c|c|c|c|c|c|c|c|}
\hline & \multirow[b]{2}{*}{$n$} & \multirow[b]{2}{*}{$\%$} & \multicolumn{4}{|c|}{ WC (cm) } & \multicolumn{4}{|c|}{ WHtR } & \multicolumn{4}{|c|}{ BMI $\left(\mathrm{kg} / \mathrm{m}^{2}\right)$} \\
\hline & & & $\mathrm{aOR}$ & $95 \% \mathrm{Cl}$ & AUC & $95 \% \mathrm{Cl}$ & aOR & $95 \% \mathrm{Cl}$ & AUC & $95 \% \mathrm{Cl}$ & aOR & $95 \% \mathrm{Cl}$ & AUC & $95 \% \mathrm{Cl}$ \\
\hline \multicolumn{15}{|c|}{ Male Arab (N 1417) } \\
\hline Diabetes & 146 & $10 \cdot 30$ & 1.04 & $1.02,1.05$ & 0.72 & $0.68,0.76$ & 1.07 & $1.04,1.09$ & 0.72 & $0.68,0.76$ & 1.07 & $1 \cdot 04,1 \cdot 10$ & 0.71 & $0.67,0.75$ \\
\hline$\geq 3 \mathrm{CVD}$ risks & 377 & 26.61 & 1.04 & $1.03,1.05$ & 0.67 & $0.64,0.70$ & 1.06 & $1.05,1.08$ & 0.66 & $0.63,0.69$ & 1.08 & $1.06,1 \cdot 11$ & 0.66 & $0.63,0.69$ \\
\hline \multicolumn{15}{|c|}{ Female Arab (N 1294) } \\
\hline Diabetes & 90 & 6.96 & 1.07 & $1.05,1.09$ & 0.81 & $0.78,0.85$ & 1.12 & $1.09,1.15$ & 0.81 & $0.77,0.85$ & 1.11 & $1 \cdot 07,1 \cdot 15$ & 0.79 & $0.75,0.83$ \\
\hline$\geq 3 \mathrm{CVD}$ risks & 183 & 14.14 & 1.05 & $1.04,1.07$ & 0.75 & $0.71,0.78$ & 1.09 & $1.06,1 \cdot 11$ & 0.75 & $0.71,0.78$ & 1.09 & $1.07,1.12$ & 0.74 & $0.71,0.78$ \\
\hline \multicolumn{15}{|c|}{ Male South Asian (N609) } \\
\hline Diabetes & 87 & 14.29 & 1.07 & $1.05,1 \cdot 10$ & 0.73 & $0.68,0.79$ & 1.13 & $1.08,1.18$ & 0.73 & $0.68,0.79$ & $1 \cdot 17$ & $1 \cdot 11,1 \cdot 24$ & 0.74 & $0.68,0.79$ \\
\hline$\geq 3$ CVD risks & 210 & 34.48 & 1.06 & $1.04,1.08$ & 0.66 & $0.62,0.71$ & 1.11 & $1.07,1.15$ & 0.68 & $0.64,0.72$ & $1 \cdot 12$ & $1.07,1.17$ & 0.66 & $0.61,0.70$ \\
\hline \multicolumn{15}{|c|}{ Female South Asian (N 269) } \\
\hline Diabetes & 26 & $9 \cdot 67$ & 1.04 & $1.00,1.08$ & 0.79 & $0.70,0.87$ & 1.06 & $1 \cdot 00,1 \cdot 11$ & 0.79 & $0.70,0.87$ & $1 \cdot 11$ & $1.03,1 \cdot 20$ & 0.79 & $0.71,0.87$ \\
\hline$\geq 3 \mathrm{CVD}$ risks & 53 & $19 \cdot 70$ & 1.02 & $1.00,1.05$ & 0.71 & $0.63,0.78$ & 1.03 & $0.99,1.08$ & 0.71 & $0.64,0.79$ & 1.07 & $1.01,1 \cdot 13$ & 0.73 & $0.66,0.80$ \\
\hline
\end{tabular}

WC, waist circumference; WHtR, waistheight ratio; BMI, body mass index.

Table 3. Cut-off values of waist circumference (WC), waist:height ratio (WHtR) and BMI that are predictive of the metabolic syndrome risk factors in South Asia and Arab males and females

\begin{tabular}{|c|c|c|c|c|c|c|c|c|c|c|c|c|c|c|c|}
\hline & \multicolumn{5}{|c|}{ WC $(\mathrm{cm})$} & \multicolumn{5}{|c|}{ WHtR } & \multicolumn{5}{|c|}{ BMI $\left(\mathrm{kg} / \mathrm{m}^{2}\right)$} \\
\hline & $\begin{array}{l}\text { Cut- } \\
\text { off }\end{array}$ & $\begin{array}{c}\text { Sensitivity } \\
(\%)\end{array}$ & $\begin{array}{c}\text { Specificity } \\
(\%)\end{array}$ & $\begin{array}{c}\text { PPV } \\
(\%)\end{array}$ & $\begin{array}{l}\text { NPV } \\
(\%)\end{array}$ & $\begin{array}{l}\text { Cut- } \\
\text { off }\end{array}$ & $\begin{array}{c}\text { Sensitivity } \\
(\%)\end{array}$ & $\begin{array}{c}\text { Specificity } \\
(\%)\end{array}$ & $\begin{array}{l}\text { PPV } \\
(\%)\end{array}$ & $\begin{array}{l}\text { NPV } \\
(\%)\end{array}$ & $\begin{array}{l}\text { Cut- } \\
\text { off }\end{array}$ & $\begin{array}{c}\text { Sensitivity } \\
(\%)\end{array}$ & $\begin{array}{c}\text { Specificity } \\
(\%)\end{array}$ & $\begin{array}{l}\text { PPV } \\
(\%)\end{array}$ & $\begin{array}{l}\text { NPV } \\
(\%)\end{array}$ \\
\hline \multicolumn{16}{|l|}{ Male Arab } \\
\hline Diabetes & 106 & 67 & 66 & 19 & 95 & 0.55 & 72 & 60 & 17 & 95 & 28 & 70 & 62 & 17 & 95 \\
\hline$\geq 3$ CVD risks & 97 & 68 & 57 & 36 & 83 & 0.55 & 64 & 60 & 37 & 82 & 28 & 86 & 38 & 33 & 88 \\
\hline \multicolumn{16}{|l|}{ Female Arab } \\
\hline Diabetes & 107 & 82 & 71 & 17 & 98 & 0.65 & 86 & 63 & 15 & 98 & 33 & 77 & 71 & 17 & 98 \\
\hline$\geq 3 \mathrm{CVD}$ risks & 93 & 72 & 67 & 27 & 94 & 0.60 & 84 & 55 & 24 & 95 & 30 & 71 & 68 & 27 & 93 \\
\hline \multicolumn{16}{|l|}{ Male South Asian } \\
\hline Diabetes & 92 & 71 & 2 & 26 & 93 & 0.56 & 80 & 58 & 24 & 95 & 23 & 84 & 54 & 23 & 95 \\
\hline$\geq 3$ CVD risks & 91 & 54 & 70 & 49 & 74 & 0.52 & 70 & 58 & 47 & 79 & 25 & 74 & 52 & 45 & 79 \\
\hline \multicolumn{16}{|l|}{ Female South } \\
\hline Diabetes & 91 & 96 & 56 & 19 & 99 & 0.57 & 96 & 56 & 19 & 99 & 26 & 88 & 60 & 19 & 98 \\
\hline$\geq 3$ CVD risks & 93 & 72 & 68 & 35 & 91 & 0.49 & 68 & 69 & 35 & 90 & 32 & 75 & 63 & 33 & 91 \\
\hline
\end{tabular}




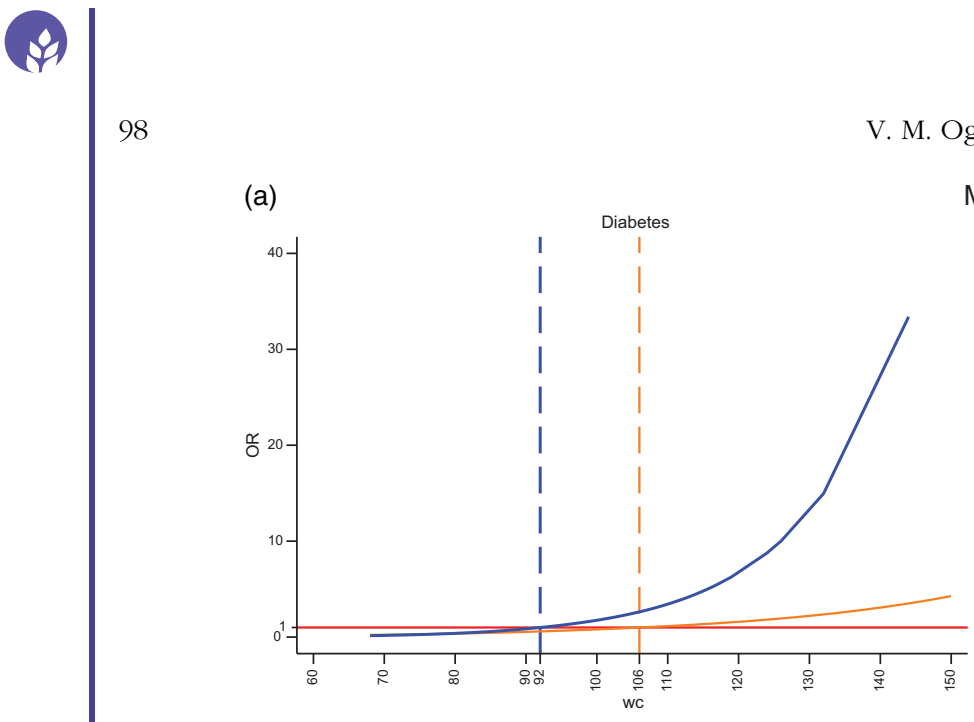

Male
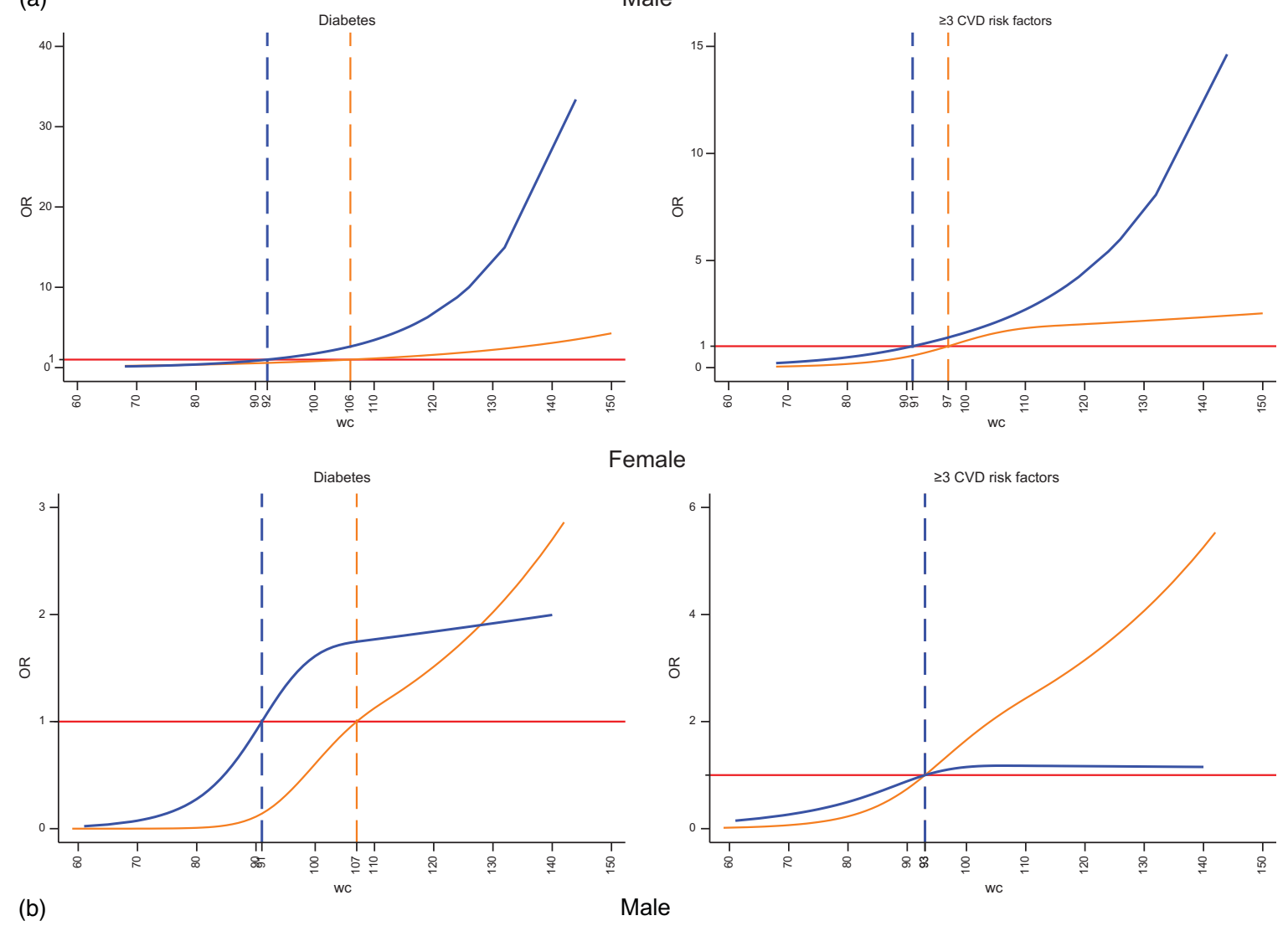

(b)
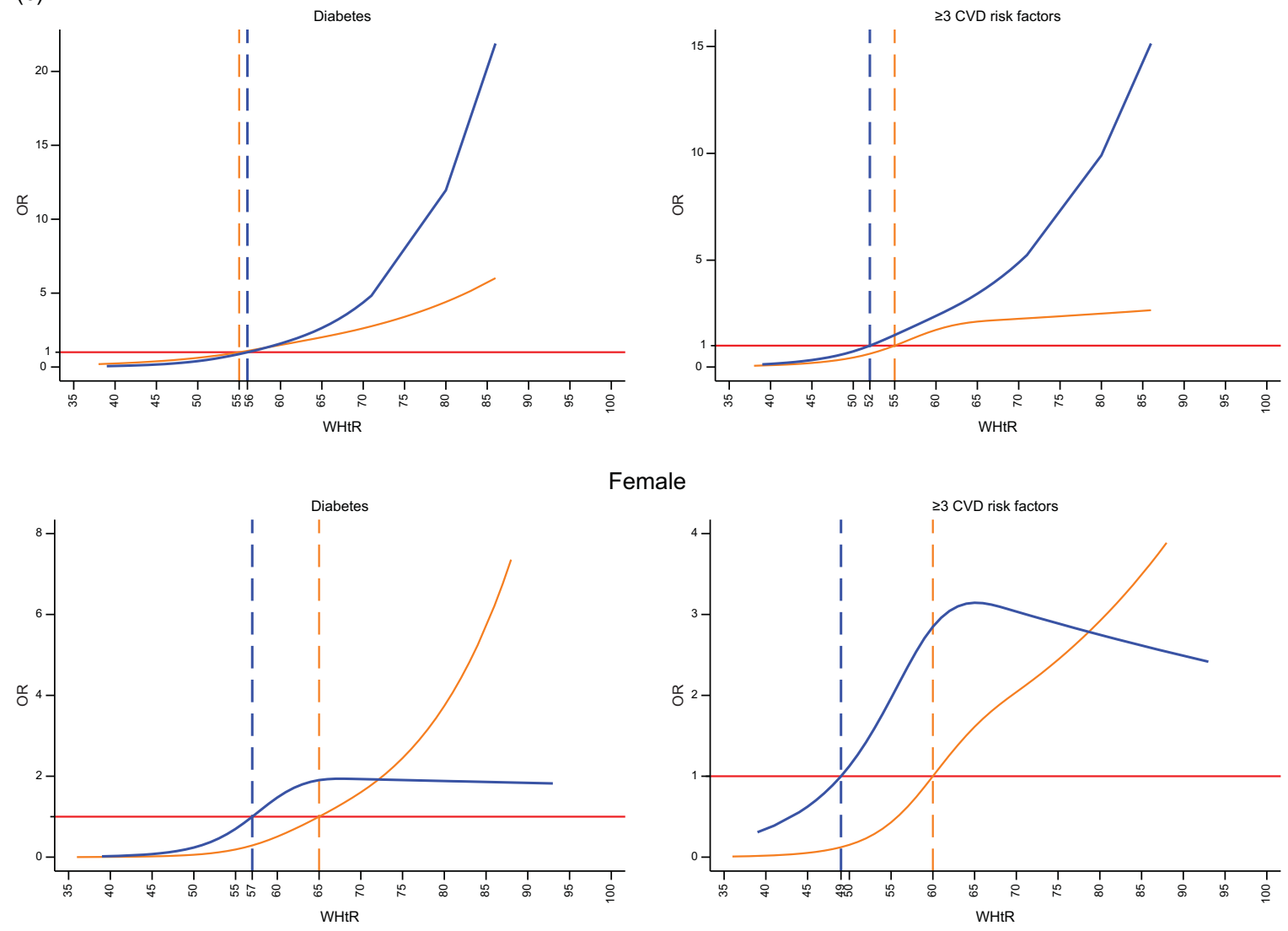

Fig. 2. Areas under the receiver operating characteristics (AUROC) curves for (a) waist circumference (WC), (b) waist:height ratio (WHIR) and (c) BMI, across sex and ethnic group. $=$ Arab; $\longrightarrow$ South Asia. 
(c)
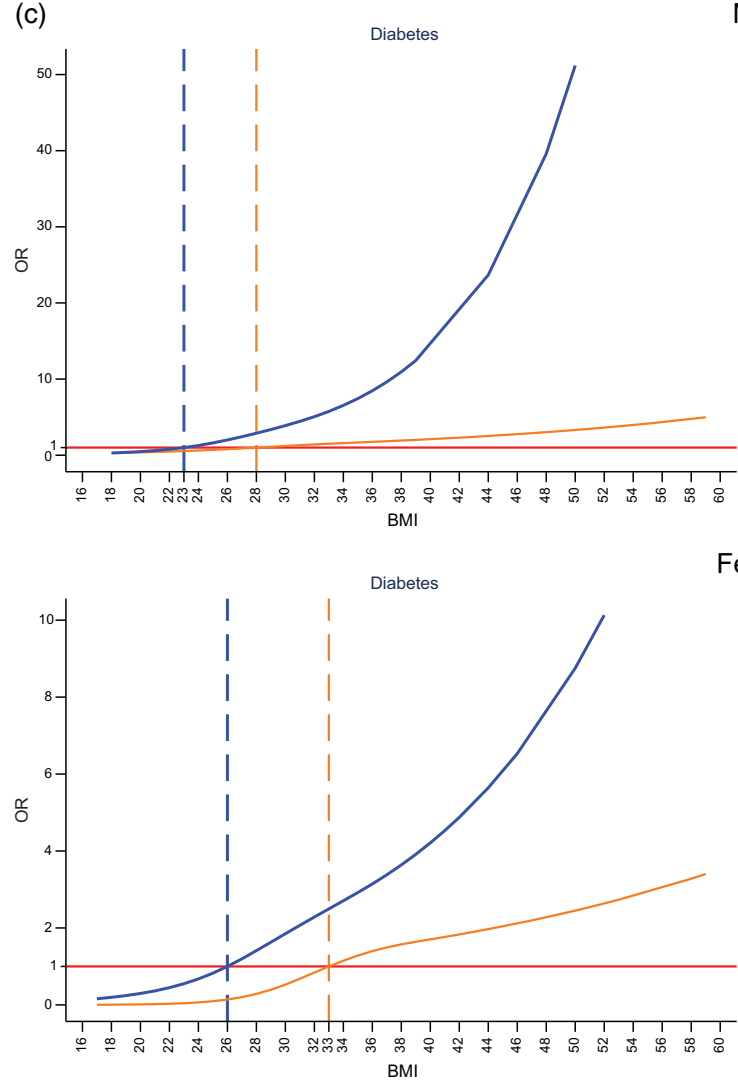

Fig. 2. (continued)

highest AUC and predicted the MetS better than WC and WHtR among adults 35-65 years in the West of Iran. In a Qatari population above 20 years of age, Bener et al. ${ }^{(39)}$ reported that for men and women, WC was a better predictor of the MetS compared with WHtR and BMI. Also, in Jordan, Khader et al. ${ }^{(40)}$ found that the WHtR performed better than other anthropometric indices with an AUC $>80$. Given that our population of Arabs comprises individuals from different Arab nations and our findings show marginal differences in the predictive ability of these anthropometric indices, relying on one index in the Arab Kuwaiti population may be appropriate.

The age-adjusted odds of diabetes and $\geq 3$ CVD risk factors was higher per single unit increase for BMI compared with WHtR and WC. It has been argued that BMI is not always the best measure of obesity given that it is not an accurate indicator for individuals with extreme obesity ${ }^{(41)}$; can overestimate the level of body fat among pregnant women ${ }^{(42,43)}$ and physically active individuals and athletes ${ }^{(44)}$; or can underestimate the amount of body fat in the elderly ${ }^{(45)}$. In a study comparing the gold standard dual X-ray absorptiometry with anthropometry, Day et al. ${ }^{(46)}$ found that WC was more strongly correlated with dual $\mathrm{X}$-ray absorptiometry, than WHtR and BMI. Therefore, there is an indication that the higher odds of co-morbidities with increasing BMI may be a presentation of our highly obese study population, especially among the Arab groups, given that the population mean of BMI seats around class 1 obesity $\left(>30 \mathrm{~kg} / \mathrm{m}^{2}\right)$.
Male

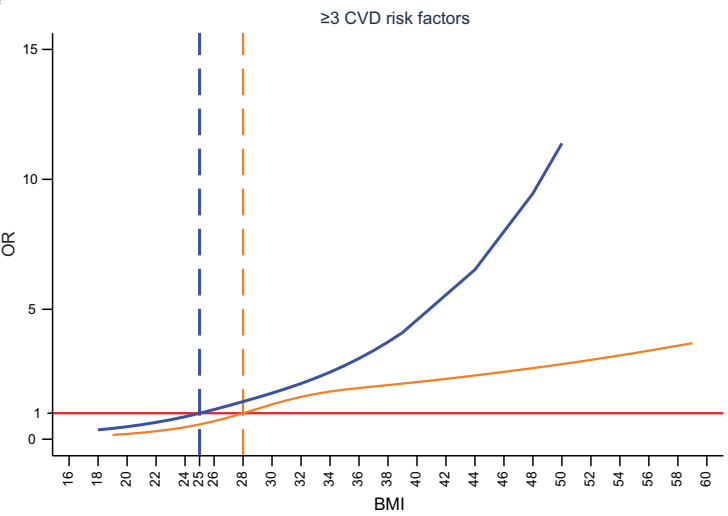

Female

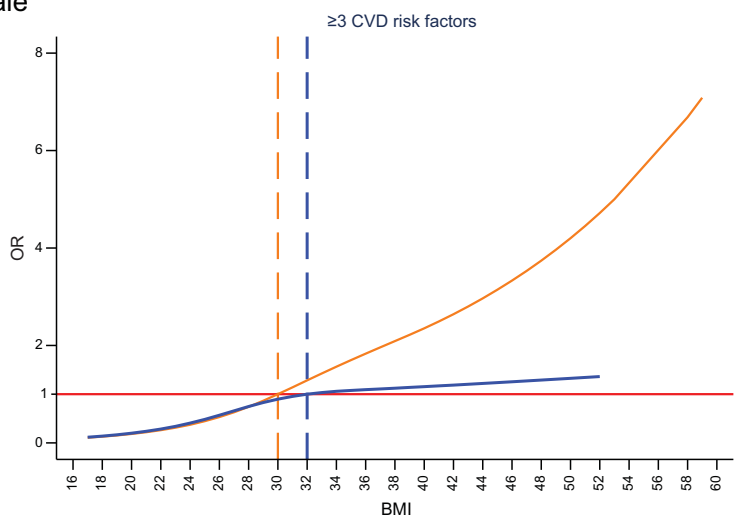

The optimal WC cut-off points in our study population were different from the IDF for Arabs and South Asians, especially among women. In contrast to IDF WC cut-off of $80 \mathrm{~cm}$ for Arab women, our findings of the optimal cut-off point of $93 \mathrm{~cm}$ for $\geq 3 \mathrm{CVD}$ risk factors are in agreement with other studies from the Middle East and Mediterranean region ${ }^{(38,47,48)}$. For men in the Arab group, the optimal WC for $\geq 3$ CVD and individual risk factors such as diabetes were $106 \mathrm{~cm}$ and $97 \mathrm{~cm}$, respectively. The findings suggest that the IDF-recommended WC threshold should be increased for Arab women to identify women with greater risk of diabetes and the MetS and eliminate the potential for overdiagnosis.

We also found that the optimal range of WC for predicting diabetes and $\geq 3$ CVD risk factors amongst South Asian expatriates in Kuwait was 92 and $91 \mathrm{~cm}$ for men and 91 and $93 \mathrm{~cm}$ for women, respectively. Mohan et al. ${ }^{(49)}$ found that WC of $87 \mathrm{~cm}$ for men and $82 \mathrm{~cm}$ for women appear to be the appropriate cut-off point to identify cardiometabolic risk factors in urban Indians. Another study of British South Asians ${ }^{(50)}$ showed that equivalent rates of diabetes occur at lower obesity levels than the Caucasian cut-off of $>102 \mathrm{~cm}$ for men and $>88 \mathrm{~cm}$ for women, thus supporting the need for ethnic-specific cut-off values. However, given that the expression of cardiometabolic risks is not dependent on genetic factors alone, the moderating role of environment which shapes collective health and health-related behaviours is relevant too. As Kuwait has one of the highest 


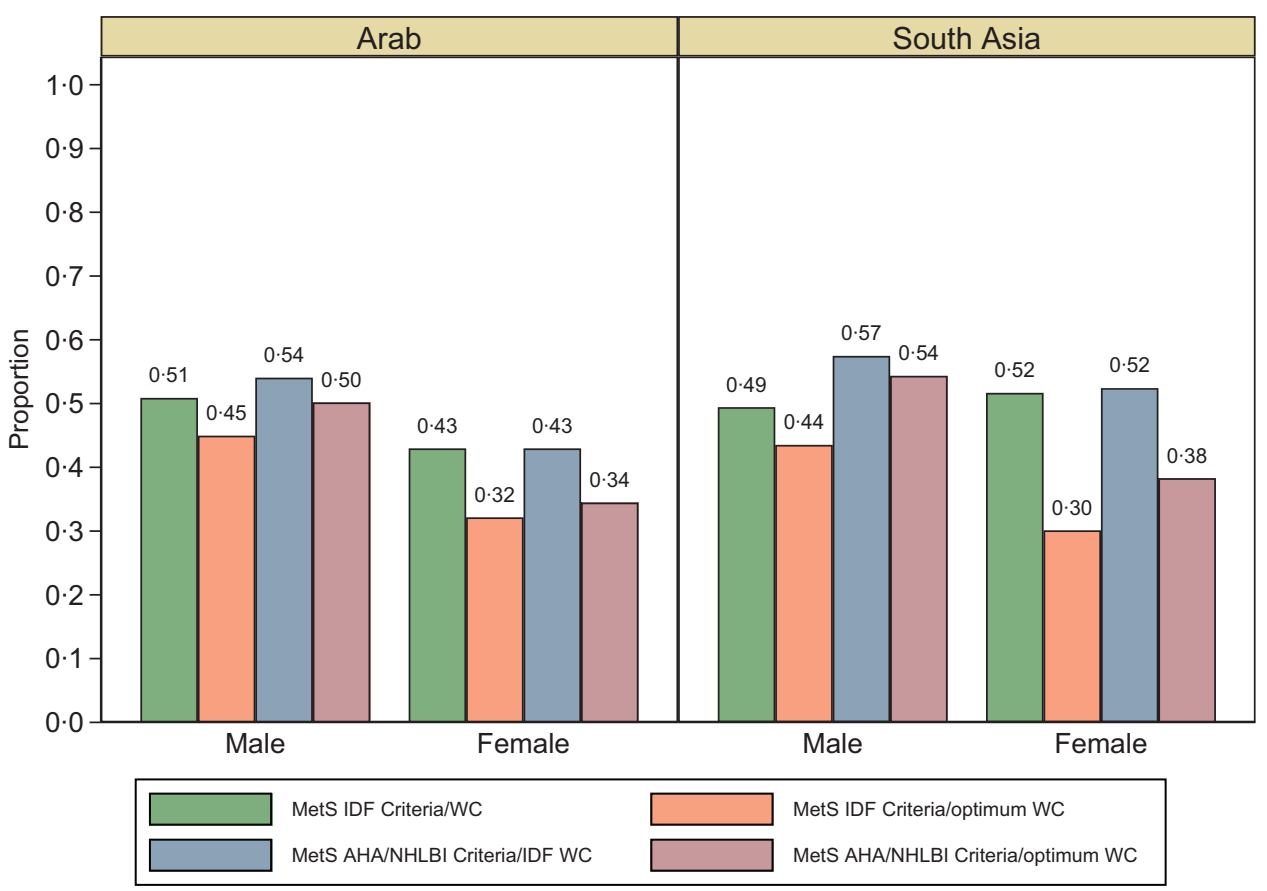

Fig. 3. Prevalence of MetS based on IDF and AHA/NHLBI criteria using the IDF ethnic cut-off points and the predicted sample-specific optimum WC cut-off across sex and ethnic group.

burdens of obesity and physical inactivity globally, environmental predispositions orchestrating the burden of obesity and physical inactivity are likely to result in higher general and abdominal obesity, especially among women.

Our study also showed that the optimal WHtR cut-off was consistently above the recommended global value (0.50), especially for all sexes in the Arab group (0.55 men and $0.60-0.65$ women). Ashwell \& Hsieh ${ }^{(51)}$ have proposed that WHtR could be a better, simple and rapid screening tool than $\mathrm{BMI}$ given that it is easier to measure and calculate, and the simple public health message of keeping the WC less than half of height is more intuitive. However, in South Asian men for both diabetes and $\geq 3$ CVD risk factors, the exponential rise in the OR following a single unit increase in anthropometric indices, compared with Arab men, signifies potential higher morbidity/mortality among South Asians at lower WC, WHtR or BMI. Our findings support the existing evidence that Asians have an ethnic predisposition to adverse body fat distribution and the MetS at lower cut-off points for anthropometric indices ${ }^{(52,53)}$

Studies suggest that fat distribution measured by WC or WHtR is more important than total body fat based on BMI for CVD ${ }^{54,55)}$. The exponential increase in the OR and plateauing after the predicted cut-off points is more pronounced in South Asian women for WC and WHtR, than BMI. This finding may suggest that South Asian women tend to have a stable risk after the anthropometric cut-off point that predicts increased risk, given their predisposition to adverse body fat and CVD risk at lower cut-off points. The risk of CVD within a given WC strata has been shown to significantly differ between shorter and taller individuals ${ }^{(56)}$. Therefore, the contribution of height to WC may have influenced the shape of the relationship between WHtR and diabetes and $\geq 3$ CVD risk factors in South Asian women compared with Arab women.
We further assessed the prevalence of the MetS as defined by IDF and AHA/NHLBI using the optimal WC derived from $\geq 3$ CVD risk factor to compare with the IDF-recommended cut-off points for Arabs and South Asians. We found that irrespective of the definition used, the IDF-specified cut-off values led to a higher prevalence of the MetS than when the optimal WC cut-off is used. Evidence had shown that obesity does not invariably lead to adverse metabolic conditions such as diabetes, hypertension, dyslipidaemia and the $\operatorname{MetS}^{(57,58)}$ Increasing evidence also indicates that the prevalence of metabolically healthy obesity differs considerably according to the WC cut-off values and the criteria used in defining the MetS ${ }^{(59,60)}$. Our predicted WC cut-off for abdominal obesity, which was higher, may be more accurate in delineating the metabolically healthy obese phenotypes in the population, thus reducing potential overdiagnosis.

\section{Strengths and limitations of the study}

The nationally representative study population and large sample size are important strengths of our study. Our comparison of Arabs and South Asians resident in Kuwait is unique and has not been previously reported. A limitation is the cross-sectional design, which precludes knowledge of temporality and causality in prognostic applications. The smaller proportion of South Asians with diabetes may have influenced the s-shaped non-linear relationship found in this subgroup.

\section{Conclusion}

This study shows that given their similar AUC, any of the anthropometric indices assessed here (WC, WHtR or BMI) could be used in screening for diabetes and $\geq 3$ CVD risk factors in Kuwait. WC and BMI cut-points for screening $\geq 3$ CVD risk factors in Arabs and South Asians in Kuwait were higher for women. 
The WHtR cut-point for screening $\geq 3$ CVD risk factors was higher in women compared with men in the Arab group but not in the South Asian group, suggesting that the global cutoff of 0.5 may be acceptable for the South Asian group. Across Arab and South Asian groups, men had a higher prevalence of the MetS than women irrespective of the WC cut-off or MetS criteria used. This study provides Kuwait-specific anthropometric cut-off values and adds to the growing call for ethnic-based cut-points for classification and comparison of populations at risk of CVD.

\section{Acknowledgements}

We are grateful to the teams at the Dasman Diabetes Institute for their contributions in conducting this study.

We also thank the Kuwait Foundation for the Advancement of Sciences for providing funding to support this study. V. M. O., N. T. C. and M. D. conceived the objective of this study; N. T. C. and M. D. secured funding; S. A. and V. M. O. processed data; V. M. O. analysed data and drafted the manuscript; V. M. O., S. A., M. A., F. H. A., A. A., F. A., N. T. C. and M. D. reviewed manuscript for important intellectual content. All authors read and approved the final manuscript.

The authors declare that there are no conflicts of interest.

\section{Reference}

1. Grundy SM (2006) Metabolic syndrome: connecting and reconciling cardiovascular and diabetes worlds. J Am Coll Cardiol 47, 1093-1100.

2. Alberti KG, Eckel RH, Grundy SM, et al. (2009) Harmonizing the metabolic syndrome: a joint interim statement of the International Diabetes Federation Task Force on Epidemiology and Prevention; National Heart, Lung, and Blood Institute; American Heart Association; World Heart Federation; International Atherosclerosis Society; and International Association for the Study of Obesity. Circulation 120, $1640-1645$.

3. Aganovic I \& Dusek T (2007) Pathophysiology of metabolic syndrome. EJIFCC 18, 3-6.

4. Carr DB, Utzschneider KM, Hull RL, et al. (2004) Intraabdominal fat is a major determinant of the national cholesterol education program adult treatment panel III criteria for the metabolic syndrome. Diabetes 53, 2087-2094.

5. Reaven GM (1988) Banting lecture 1988. Role of insulin resistance in human disease. Diabetes 37, 1595-1607.

6. Festi D, Schiumerini R, Eusebi LH, et al. (2014) Gut microbiota and metabolic syndrome. World $J$ Gastroenterol 20, 16079-16094.

7. Tamashiro KL, Sakai RR, Shively CA, et al. (2011) Chronic stress, metabolism, and metabolic syndrome. Stress 14, 468-474.

8. Simopoulos AP (2013) Dietary $n-3$ fatty acid deficiency and high fructose intake in the development of metabolic syndrome, brain metabolic abnormalities, and non-alcoholic fatty liver disease. Nutrients 5, 2901-2923.

9. Al Zenki S, Al Omirah H, Al Hooti S, et al. (2012) High prevalence of metabolic syndrome among Kuwaiti adults: a wake-up call for public health intervention. Int J Environ Res Public Health 9, 1984-1996.
10. Aguilar M, Bhuket T, Torres S, et al. (2015) Prevalence of the metabolic syndrome in the United States, 2003-2012. JAMA 313, 1973-1974.

11. Tanamas SK, Magliano DJ, Lynch B, et al. (2012) The Australian Diabetes, Obesity and Lifestyle Study. Melbourne: Baker IDI Heart and Diabetes Institute.

12. Anderson KM, Odell PM, Wilson PW, et al. (1991) Cardiovascular disease risk profiles. Am Heart J 121, 293-298.

13. Lindstrom J \& Tuomilehto J (2003) The diabetes risk score: a practical tool to predict type 2 diabetes risk. Diabetes care 26, 725-731.

14. Conroy RM, Pyorala K, Fitzgerald AP, et al. (2003) Estimation of ten-year risk of fatal cardiovascular disease in Europe: the SCORE project. Eur Heart J 24, 987-1003.

15. Stevens RJ, Kothari V, Adler AI, et al. (2001) The UKPDS risk engine: a model for the risk of coronary heart disease in Type II diabetes (UKPDS 56). Clin Sci 101, 671-679.

16. Kanellakis S, Mavrogianni C, Karatzi K, et al. (2020) Development and validation of two self-reported tools for insulin resistance and hypertension risk assessment in a European cohort: the Feel4Diabetes-study. Nutrients 12, 960.

17. Oguoma VM, Nwose EU, Skinner TC, et al. (2016) Association between metabolic syndrome and 10-year risk of developing cardiovascular disease in a Nigerian population. Int Health $\mathbf{8}$, 354-359.

18. Grundy S, Brewer H, Cleeman J, et al. (2004) Definition of metabolic syndrome: report of the national heart, lung, and blood institute/American Heart Association conference on scientific issues related to definition. Circulation 109, 433-438.

19. Babu A \& Fogelfeld L (2006) Metabolic syndrome and prediabetes. Disease-a-Month: DM 52, 55-144.

20. Balkau B \& Charles MA (1999) Comment on the provisional report from the WHO consultation. European Group for the Study of Insulin Resistance (EGIR). Diabetic Med: $\mathrm{J} \mathrm{Br}$ Diabetic Assoc 16, 442-443.

21. NCEP (2002) Third Report of the National Cholesterol Education Program (NCEP) expert panel on detection, evaluation, and treatment of high blood cholesterol in adults (Adult Treatment Panel III) final report. Circulation 106, 3143.

22. Einhorn D, Reaven GM, Cobin RH, et al. (2003) American College of Endocrinology position statement on the insulin resistance syndrome. Endocr Pract: Offic J Am Coll Endocrinol AmAssoc Clin Endocrinol 9, 237-252.

23. Grundy SM, Cleeman JI, Daniels SR, et al. (2005) Diagnosis and management of the metabolic syndrome an American Heart Association/National Heart, Lung, and Blood Institute scientific statement. Circulation 112, 2735-2752.

24. Alberti KG, Zimmet P, Shaw J, et al. (2005) The metabolic syndrome-a new worldwide definition. Lancet $\mathbf{3 6 6}$, 1059-1062.

25. Alberti KG \& Zimmet PZ (1998) Definition, diagnosis and classification of diabetes mellitus and its complications. Part 1: diagnosis and classification of diabetes mellitus provisional report of a WHO consultation. Diabetic Med: J Br Diabetic Assoc 15, 539-553.

26. Ansarimoghaddam A, Adineh HA, Zareban I, et al. (2018) Prevalence of metabolic syndrome in Middle-East countries: meta-analysis of cross-sectional studies. Diabetes Metab Syndrome 12, 195-201.

27. Simmons RK, Alberti KG, Gale EA, et al. (2010) The metabolic syndrome: useful concept or clinical tool? Report of a WHO Expert Consultation. Diabetologia 53, 600-605.

28. Zeng Q, He Y, Dong S, et al. (2014) Optimal cut-off values of BMI, waist circumference and waist:height ratio for defining obesity in Chinese adults. Br J Nutr 112, 1735-1744. 
29. Chen YM, Ho SC, Lam SS, et al. (2006) Validity of body mass index and waist circumference in the classification of obesity as compared to percent body fat in Chinese middle-aged women. Int J Obes 30, 918-925.

30. Oguoma VM, Nwose EU, Ulasi II, et al. (2016) Maximum accuracy obesity indices for screening metabolic syndrome in Nigeria: a consolidated analysis of four cross-sectional studies. Diabetes Metab Syndrome 10, 121-127.

31. Ware LJ, Rennie KL, Kruger HS, et al. (2014) Evaluation of waist-to-height ratio to predict 5 year cardiometabolic risk in sub-Saharan African adults. Nutr Metab Cardiovasc Dis: NMCD 24, 900-907.

32. Ashwell M \& Gibson S (2016) Waist-to-height ratio as an indicator of 'early health risk': simpler and more predictive than using a 'matrix' based on BMI and waist circumference. BMJ Open 6, e010159.

33. Ashwell M, Gunn P \& Gibson S (2012) Waist-to-height ratio is a better screening tool than waist circumference and BMI for adult cardiometabolic risk factors: systematic review and meta-analysis. Obes Rev: Offic I Int Assoc Study Obes 13, 275-286.

34. Oguoma VM, Coffee NT, Alsharrah S, et al. (2021) Prevalence of Overweight and Obesity, and Associations with SocioDemographic Factors in Kuwait. BMC Public Health Published online: 01 December 2021. doi: 10.1186/s12889021-10692-1.

35. WHO (2011) Use of Glycated Haemoglobin (HbA1c) in the Diagnosis of Diabetes Mellitus: Abbreviated Report of a WHO Consultation. Geneva: World Health Organization.

36. Peat J \& Barton B (2014) Medical Statistics: a Guide to Data Analysis and Critical Appraisal. Hoboken, NJ: John Wiley \& Sons.

37. Mojiminiyi OA, Al Mulla F \& Abdella NA (2009) Which obesity index best explains the link between adipokines, coronary heart disease risk and metabolic abnormalities in type 2 diabetes mellitus? Med Princ Pract 18, 123-129.

38. Hamzeh B, Bagheri A, Pasdar Y, et al. (2020) Predicting metabolic syndrome by anthropometric measures among adults 35-65 years in the west of Iran; a cross sectional study from an Iranian RaNCD cohort data. Diabetes Metab Syndrome: Clin Res Rev 14, 1293-1298.

39. Bener A, Yousafzai MT, Darwish S, et al. (2013) Obesity index that better predict metabolic syndrome: body mass index, waist circumference, waist hip ratio, or waist height ratio. $J$ Obes 2013, 269038.

40. Khader Y, Batieha A, Jaddou H, et al. (2019) The performance of anthropometric measures to predict diabetes mellitus and hypertension among adults in Jordan. BMC Public Health 19, 1416-1416.

41. Frankenfield DC, Rowe WA, Smith JS, et al. (2003) Validation of several established equations for resting metabolic rate in obese and nonobese people. J Am Dietetic Assoc 103, $1152-1159$.

42. Bosaeus M, Andersson-Hall U, Andersson L, et al. (2020) Body composition during pregnancy: longitudinal changes and method comparisons. Reprod Sci 27, 1477-1489.

43. Cedergren M (2006) Effects of gestational weight gain and body mass index on obstetric outcome in Sweden. Int J Gynaecol Obstet 93, 269-274.
44. Provencher MT, Chahla J, Sanchez G, et al. (2018) Body mass index versus body fat percentage in prospective national football league athletes: overestimation of obesity rate in athletes at the national football league scouting combine. J Strength Conditioning Res 32, 1013-1019.

45. Pasco JA, Nicholson GC, Brennan SL, et al. (2012) Prevalence of obesity and the relationship between the body mass index and body fat: cross-sectional, population-based data. PLoS One 7, e29580.

46. Day K, Kwok A, Evans A, et al. (2018) Comparison of a bioelectrical impedance device against the reference method dual energy X-ray absorptiometry and anthropometry for the evaluation of body composition in adults. Nutrients 10, 1469.

47. Mansour AA, Al-Hassan AA \& Al-Jazairi MI (2007) Cut-off values for waist circumference in rural Iraqi adults for the diagnosis of metabolic syndrome. Rural Remote Health 7, 765.

48. Ibrahim MM, Elamragy AA, Girgis H, et al. (2011) Cut off values of waist circumference and associated cardiovascular risk in Egyptians. BMC Cardiovasc Disord 11, 53.

49. Mohan V, Deepa M, Farooq S, et al. (2007) Anthropometric cut points for identification of cardiometabolic risk factors in an urban Asian Indian population. Metab Clin Exp 56, 961-968.

50. Tillin T, Sattar N, Godsland IF, et al. (2015) Ethnicity-specific obesity cut-points in the development of Type 2 diabetes - a prospective study including three ethnic groups in the United Kingdom. Diabetic Med: J Br Diabetic Assoc 32, 226-234.

51. Ashwell M \& Hsieh S (2005) Six reasons why the waist-to-height ratio is a rapid and effective global indicator for health risks of obesity and how its use could simplify the international public health message on obesity. Int J Food Sci Nutr 56, 303-307.

52. Gupta A, Gupta R, Sarna M, et al. (2003) Prevalence of diabetes, impaired fasting glucose and insulin resistance syndrome in an urban Indian population. Diabetes Res Clin Pract 61, 69-76.

53. Nestel P, Lyu R, Low LP, et al. (2007) Metabolic syndrome: recent prevalence in East and Southeast Asian populations. Asia Pac J Clin Nutr 16, 362-367.

54. Li WC, Chen IC, Chang YC, et al. (2013) Waist-to-height ratio, waist circumference, and body mass index as indices of cardiometabolic risk among 36642 Taiwanese adults. Eur J Nutr $\mathbf{5 2}$, $57-65$.

55. Janghorbani M, Aminorroaya A \& Amini M (2017) Comparison of different obesity indices for predicting incident hypertension. High Blood Press Cardiovasc Prev 24, 157-166.

56. Schneider HJ, Klotsche J, Silber S, et al. (2011) Measuring abdominal obesity: effects of height on distribution of cardiometabolic risk factors risk using waist circumference and waist-to-height ratio. Diabetes Care 34, e7.

57. Primeau V, Coderre L, Karelis AD, et al. (2011) Characterizing the profile of obese patients who are metabolically healthy. Int J Obes 35, 971-981.

58. Eckel RH, Alberti KG, Grundy SM, et al. (2010) The metabolic syndrome. Lancet 375, 181-183.

59. Velho S, Paccaud F, Waeber G, et al. (2010) Metabolically healthy obesity: different prevalences using different criteria. Eur J Clin Nutr 64, 1043-1051.

60. Pataky Z, Bobbioni-Harsch E \& Golay A (2010) Open questions about metabolically normal obesity. Int J Obes 34, S18-S23. 